\section{Occupational asthma}

In asthmatics the airways respond to a wide variety of stimuli in such a way as to produce cough, wheeze, and breathlessness. Among the factors that may induce this response are allergens, irritants, infections, exercise, changes in temperature, and emotion. People exposed at their work to grain dusts have been known at least since the time of Ramazzini to be subject to urticaria and attacks of shortness of breath. Indeed, the harvesting and use of grains give rise to dust containing many different organic particles, and not only do atopic individuals develop asthma in such environments but some non-atopic people also become sensitised. ${ }^{1}$ Other organic substances known to provoke occupational asthma include dust from wood, especially hardwoods, in carpenters and joiners, and antigens from rats and locusts among laboratory workers. Certain metals and their salts may also sensitise the airways, the best known being the complex salts of platinum, nickel, and chromium. ${ }^{2}$

Interest in occupational asthma has been reawakened recently by growing awareness that newer industries may be associated with an appreciable hazard and that simple tests of ventilatory function can now measure the responses of the airways to these hazards. Probably the first indication of trouble was the report from France in 1951 of asthma provoked by isocyanates, used in the production of polyurethane foam. ${ }^{3}$ These findings, subsequently confirmed by many other reports, identified the risk to workers in a vast and rapidly expanding industry. ${ }^{4}$ Recent work has shown that, once sensitised, workers may develop prolonged and severe attacks of asthma after even very small exposures. ${ }^{5}$ Other recent technological changes that present a risk of occupational asthma include the introduction of proteolytic enzymes into washing powders, ${ }^{6}$ the widespread use of epoxy resins, ${ }^{7}$ the production of new antibiotics and pharmaceuticals, ${ }^{8}$ and the use of solders in the manufacture of electronic circuitry. ${ }^{9}$

Occupationally provoked wheezing may occur in a patient who already has asthma or has suffered from it, or in someone who has always been well. In the latter case symptoms will usually disappear when exposure ceases, though there is always the risk that occupational exposure will trigger permanent and disabling asthma. The diagnosis is often made by the patient himself recognising the relation between symptoms and work, though this may be obscured if the bronchial response to the sensitiser occurs several hours after exposure or is prolonged. ${ }^{5}$ Confirmation of the diagnosis is straightforward: the patient simply needs to be shown how to monitor his peak flow rate (using, for example, the mini Wright peak flow meter ${ }^{10}$ ) over a period of work and holiday or sick leave. Identifying the sensitiser may be more difficult, since it may call for intimate knowledge of the chemical processes in a particular factory.

Once the diagnosis has been made the ideal is to avoid the offending agent. Short of this, prophylactic treatment with cromoglycate, bronchodilators, or inhaled steroids may be effective, though in principle this is the wrong approach. At present, industrial injury compensation is not available even to patients who lose their jobs or become seriously disabled by occupational asthma. This question is, however, being considered by the Industrial Injuries Advisory Board. Finally, there remains a considerable challenge to occupational physicians and hygienists-to determine how far concentrations of known airborne allergens need to be reduced to prevent sensitisation.
1 Herxheimer, H, Acta Allergologica, 1973, 28, 42.

2 Seaton, A, in Occupational Lung Diseases, ed W K C Morgan and A Seaton, p 251. Philadelphia, Saunders, 1975.

${ }^{3}$ Fuchs, S, and Valade, P, Archives des Maladies Professionnelles de Médecine du Travail et de Sécurité Sociale, 1951, 12, 191.

${ }^{4}$ Peters, J M, Proceedings of the Royal Society of Medicine, 1970, 63, 372.

5 Burge, P S, O'Brien, I M, and Harries, M G, Thorax, 1979, 34, 317.

${ }^{6}$ Flindt, M L H, Lancet, 1969, 1, 1177.

${ }^{7}$ Fawcett, I W, Newman, A J and Pepys, J, Clinical Allergy, 1977, 7, 1.

${ }^{8}$ Davies, R J, Hendrick, D J, and Pepys, J, Clinical Allergy, 1974, 4, 227.

9 Burge, P S, et al, Thorax, 1979, 34, 13.

10 Wright, B M, British Medical fournal, 1978, 2, 1627.

\section{High summer's medicopolitics}

High summer has been short on sun but long on medicopolitics. Only history can tell which of the summer's many medicopolitical events will leave a permanent mark on the NHS. At this short perspective all that can be done is to list the likely candidates. Will the new Government's plans to change the style of running the NHS ${ }^{1}$ - with less Whitehall "nannying" and more local power-and to revive the symbiosis between private and state medicine ${ }^{2}$ have the effect that Tory politicians hope for? Will the 1979 Review Body report, ${ }^{3}$ which destroyed consultants' hopes for a new worksensitive contract, go down in history because it prompted a remarkable salvage attempt on the old contract and a thorough reorganisation of the review system itself ? Or will any of the decisions made during the BMA's very successful conference month prove to be a front runner in changing the course of the Health Service? Or could perhaps that imminent event, the report of the Royal Commission on the NHS, yet overshadow all else in 1979 ?

We have not seen all the details of the Government's intentions for the NHS, and, despite the inevitable leaks, speculation on the Royal Commission's report is pointless so close to its publication. But the outcome of the five craft conferences and the Annual Representative Meeting (reported in recent issues) is known and shows that the BMA is as much interested in patients as in pay and is not prepared to sacrifice professional standards in pursuit of unionisation. But what of the context of these decisions? The pattern of the five craft conferences being held in the run up to the ARM was a major part of the BMA's reorganisation ${ }^{4}$ and this year the new machinery was seen to be well and truly run in. The subjects discussed were usually pertinent, the standards of debates were generally high, and there was remarkably little acrimony, which was not for lack of contentious material. Thus the policies approved this summer can reasonably be said to represent the profession's aims.

And what are these? Well, its aims are many, but a distillation of them would contain the following ingredients. Maintenance of high standards of care under professional control; greater attention to confidentiality, particularly where computers are concerned; the doctor should lead the clinical team; resolution of the manpower, training, and career problems; modification of the Review Body system (though the juniors still reject the Review Body); strengthening of preventive medicine and health education; a proper balance between unionisation and professional objectives; and more power to doctors in the periphery.

For some time doctors have been warily toying with the idea of clinical audit for preserving professional standards. 